(C2020. This manuscript version is made available under the CC-BY-NC-ND 4.0 license http://creativecommons.org/licenses/by-nc-nd/4.0/

Composites Part A vol 131 (2020) 105782

Doi: https://doi.org/10.1016/j.compositesa.2020.105782

\title{
Drop weight impact behaviour of viscoelastically prestressed composites.
}

\author{
Yang Qin ${ }^{\mathrm{a}, \mathrm{b}}$, Kevin S. Fancey ${ }^{\mathrm{a}, *}$ \\ ${ }^{a}$ Department of Engineering, University of Hull, HU6 7RX, UK \\ ${ }^{b}$ School of Engineering, Computing \& Mathematics, University of Plymouth, PLA 8AA, UK
}

\begin{abstract}
Viscoelastically prestressed polymeric matrix composites (VPPMCs) are produced by subjecting fibres to tensile creep, the creep load being released prior to fibre moulding. Following matrix curing, the viscoelastically recovering fibres generate compressive stresses within the matrix which, from previous studies, can improve mechanical properties by up to $50 \%$. This paper reports on the first study of thin flatplate VPPMCs, using nylon 6,6 fibre-polyester resin to form cross-fibre composite plates (CCPs) with $0^{\circ} / 90^{\circ}$ fibre layers and randomly distributed discontinuous fibre plates (RCPs). Drop-weight impact testing was performed on CCPs with impact velocities of $1.9-5.8 \mathrm{~m} / \mathrm{s}$ and, compared with (unstressed) control samples, VPPMC damage depth was reduced by up to $29 \%$; however, this difference decreased with impact velocity, indicating little improvement above $7.7 \mathrm{~m} / \mathrm{s}$. RCPs, tested at $3.0 \mathrm{~m} / \mathrm{s}$, showed a $\sim 30 \%$ reduction in VPPMC damage depth, compared with $\sim 20 \%$ for CCPs, but with no changes in debonded area.
\end{abstract}

Keywords: A. Polymer-matrix composites (PMCs); B. Impact behaviour;

D. Mechanical testing; Viscoelasticity.

\footnotetext{
* Corresponding author. Tel.: + 441482465071.

E-mail address: k.s.fancey@hull.ac.uk (K.S. Fancey).
} 


\section{Introduction}

\subsection{Background}

The benefits offered by fibre-reinforced polymeric matrix composites (PMCs), such as high specific strength and stiffness, have led to their adoption in a wide variety of environments, often replacing more traditional materials such as aluminium alloys and steels [1]. In practice, PMCs are commonly in the form of plates or sheets with thermosetting matrices and their response to localised impact loading is significantly different to that of metals. Clearly, most impact events on PMC plate structures will occur in the transverse direction but these usually have limited ability to undergo plastic deformation and the lack of through-thickness reinforcement means that transverse damage resistance is very poor [1-3]. Moreover, impact damage, especially at low velocities, is commonly viewed as one of the most severe threats to composite structures [4]. For example, low velocity impacts occur in marine environments, where marine composites are normally polyester resin matrices with low glass fibre volume fractions [3]. Thus investigation of low velocity impact behaviour is of major importance and has attracted significant interest, particularly with regard to improving the performance of flat plate composites.

Various methods have been investigated to improve flat plate PMC impact toughness, which have been evaluated by low velocity (drop-weight) impact testing. These include using interleaving and short fibre reinforcement [5] or thin plies [6] in carbon fibre PMC laminates and producing composites with 3D woven fabrics [7-11] to increase damage resistance. Nevertheless, in recent years, two techniques to improve impact toughness have become apparent, which are of particular interest in our work: (i) incorporating thermoplastics into a brittle matrix and (ii) the use of fibre prestressing.

For (i), the exploitation of thermoplastic materials has been a prominent feature in the goal to improve drop-weight impact toughness. Bensadoun et al [4] demonstrated that matrix toughness had a significant influence on the impact response of flax composites. The energy absorption at perforation for flax-MAPP (thermoplastic matrix) composites was more than $50 \%$ higher than flax-epoxy composites, with a decrease in impact damage area of up to 59\%. Thermoplastics have been added to thermoset (brittle) matrix PMCs by various methods. Bull et al. [12] found that the addition of thermoplastic particles to CFRP composites promoted toughening mechanisms such as particle-resin debonding, crack-deflection and, in particular, crack-bridging. Hogg and co-workers [13, 14] found that the addition of thermoplastic fibres to both glass and carbon fibre PMCs significantly increased energy absorption.

Interest in (ii) for flat plate PMCs has been less prevalent. Jevons [15] studied the impact behaviour of elastically prestressed E-glass/epoxy laminates. In terms of delamination area and energy absorption, it was found that prestress appeared to have no effect when the PMCs were subjected to high-velocity gas gun impact; however, a decrease of the delamination area up to $25 \%$ was observed compared with unstressed laminates under (low-velocity) drop-weight impact conditions.

The production of elastically prestressed PMCs (EPPMCs) follows the principles used for prestressed concrete. Thus fibres (e.g. glass) are subjected to tensile stress to maintain an elastic strain during matrix curing. The fibre tension is then released after curing, resulting in compressive stresses being generated within the solid matrix, these being counterbalanced by residual fibre tension. Various studies on EPPMCs based on laminates and simple unidirectional fibre samples have demonstrated mechanical property improvements (stiffness, strength, fatigue and impact resistance) of typically 20-50\%, compared with unstressed equivalents. Further details can be found in a recent review by Mostafa et al [16]. There are however, two potential drawbacks. First, fibre length, orientation and spatial distribution may be compromised by the need to apply fibre tension as the matrix cures [17] and it has been reported that stretching equipment design can be technically challenging $[18,19]$. Second, since the matrix is a polymeric material, localised fibre-matrix creep at the fibre-matrix regions may cause the elastic prestress to deteriorate with time [17]; some evidence of this has been recently reported [20]. The purpose of this paper is to report on the first findings from flat plate composites in which fibre prestress has been achieved through viscoelastic means, as an alternative approach to EPPMCs. 


\section{$1.2 \quad V P P M C s$}

Viscoelastically prestressed polymeric matrix composites (VPPMCs) were first investigated 20 years ago [21]. By utilising reinforcing fibres with viscoelastic properties, a VPPMC is produced by subjecting the fibres to a tensile creep load over a predetermined time period. Following load removal, the loose fibres are moulded in a resin matrix and, after the resin cures, the viscoelastically recovering fibres produce compressive stresses within the matrix. As with EPPMCs, the matrix compression is counterbalanced by residual fibre tension. One of the major benefits of VPPMCs over EPPMCs is that the fibre stretching and moulding processes are decoupled, which can enable greater flexibility in producing composite structures with complex geometries. This arises from (i) the fibre stretching equipment being relatively simple, (ii) following the stretching sequence, fibres can be cut to any length and moulded in any orientation and (iii) there are no geometrical limitations [22]. Another potential benefit is longevity. In contrast with EPPMCs, long-term viscoelastic recovery mechanisms within VPPMCs should counteract localised fibre-matrix creep [17]. Evidence of this comes from an accelerated aging (time-temperature superposition) study, which demonstrated that nylon fibre-based VPPMCs show no degradation in Charpy impact properties over a period equivalent to 25 years at a constant $50^{\circ} \mathrm{C}$ [23].

Previous investigations have demonstrated improvements in tensile and flexural properties with nylon 6,6, ultra-high molecular weight polyethylene (UHMWPE) and cellulose fibre-based VPPMCs, ranging from 15-50\% compared with unstressed counterparts [24-27]. Exploitation of the residual stress from VPPMCs to create bistable (morphing) structures has been successfully demonstrated, which may, for example, have aerospace applications [28, 29]. Of particular interest however, is the impact behaviour of VPPMCs. In Charpy tests, increases in impact energy absorption of $25-50 \%$ and $~ 20 \%$ were observed for nylon 6,6 and UHMWPE fibre-based VPPMCs respectively, compared with unstressed counterparts [17, 21, 23, 26, 30-32]. Nevertheless, these Charpy impact studies have been limited to simple beamshaped samples with unidirectional continuous fibres, i.e. effectively one-dimensional samples. Of major importance is whether viscoelastically generated prestress could be applied to improve the impact resistance of flat plate PMCs, these being closer to representing composite structures in real engineering applications.

In this paper, we report on a simple hand lay-up method to produce flat plate VPPMCs using continuous fibre layers. Drop weight impact testing has been used to evaluate their impact behaviour at three different velocities. Moreover, we report on the first production and testing of composite plates with prestress generated from randomly distributed discontinuous fibre reinforcement. To produce these samples relies on processing principles that are clearly unique to VPPMC methodology.

\section{Experimental procedures}

\subsection{Sample production}

Two types of composite plate were produced; (i) a cross-composite plate (CCP) with two continuous fibre layers at $0^{\circ}$ and $90^{\circ}$ directions (not interweaved); (ii) a random-fibre composite plate (RCP) with randomly distributed discontinuous fibres (nonwoven, fibre lengths of $100 \mathrm{~mm}$ ).

The fibre reinforcement was untwisted continuous nylon 6,6 yarn supplied by Ogden Fibres Ltd, UK. Each yarn consisted of 140 filaments with a filament diameter of $27.5 \mu \mathrm{m}$. Two identical yarns (one designated as "test", the other as "control") were annealed in a fan-assisted oven at $150{ }^{\circ} \mathrm{C}$ for $0.5 \mathrm{~h}$ to remove any residual stresses induced during manufacture. Following annealing, the test yarn was stretched under a $330 \mathrm{MPa}$ tensile creep stress for $24 \mathrm{~h}$ using a bespoke stretching rig. Meanwhile, the control yarn was positioned in close proximity to the rig, so that both yarns were exposed to the same ambient conditions $\left(20-21{ }^{\circ} \mathrm{C}, 35-45 \% \mathrm{RH}\right)$. After releasing the load, both yarns for CCP production were cut into appropriate lengths and each yarn was then brushed into two unidirectional fibre layers (one 
for $0^{\circ}$, the other for $90^{\circ}$ ). Both yarns for RCPs were cut into $100 \mathrm{~mm}$ lengths before being manually arranged into two randomly-distributed, nonwoven discontinuous fibre mats (one for the "test" sample, the other for the "control"). A fibre length significantly shorter than $100 \mathrm{~mm}$ would have been preferred for RCP production, since the longer fibre length increased processing difficulties. Nevertheless, since the critical fibre length for load transfer (a significant parameter for composite performance) has been estimated to exceed $25 \mathrm{~mm}$ in similar composites [25], the use of $100 \mathrm{~mm}$ fibre lengths ensured that the critical fibre length would be exceeded.

Before moulding the RCPs, fibre density and orientation distributions of the nonwoven fibre mats were investigated and adjusted to be approximately randomly distributed, using the image processing toolbox in Matlab software. First, an optical image of the nonwoven fibre mat was taken on a black background to maximise fibre contrast. For the fibre density distribution (FDD), this image was divided equally into 9 square grids. The total pixel brightness value of each grid was then computed, which provided an indication of the relative fibre spatial density in each grid, i.e. the FDD. Evaluation of the fibre orientation distribution (FOD) was based on the concept of two-dimensional Fourier transformation, this being suitable for representing textured images. The possible dominant fibre directions, which represent the main directions of brightness dividing lines (fibres against a black background) in the spatial domain, correspond to large magnitude of frequency components distributed along straight lines in the Fourier spectrum (frequency domain) [33]. Thus the FOD can be provided. The fibre preparation process took $\sim 1 \mathrm{~h}$ and $\sim 4 \mathrm{~h}$ for CCPs and RCPs respectively prior to moulding.

The matrix material used for this work was a clear-casting polyester resin, i.e. Reichhold Polylite 32032, mixed with 2\% MEKP catalyst, supplied by MB Fibreglass, UK. Both CCPs and RCPs were produced by open-casting with two identical PTFE moulds, one for VPPMC samples, and the other for the (unstressed) control samples. Each mould consisted of a $3 \mathrm{~mm}$ deep, $140 \times 140 \mathrm{~mm}$ square cavity with four manually operated ejection pins to facilitate the demoulding process. Test and control composite plates were moulded simultaneously with the prepared unidirectional fibre layers (for CCPs) or nonwoven fibre mats (for RCPs). Thus each batch consisted of one test and one control sample, with sample dimensions of $140 \times 140 \times 3 \mathrm{~mm}$. Owing to capacity limitations of the yarn stretching rig, the fibre volume fraction $\left(V_{\mathrm{f}}\right)$ for all samples was $2 \%$. Following demoulding, to prevent distortion from residual stresses, plates were held under steel weights in ambient conditions $\left(19-21^{\circ} \mathrm{C}\right)$ for 2 weeks prior to impact testing.

\subsection{Drop weight impact tower}

A drop weight impact testing tower was developed [34] and subsequently optimised to conduct the impact tests, as shown in Fig. 1. The projectile employed in this study was a $532.9 \mathrm{~g}$ stainless steel ball with a diameter of $50.8 \mathrm{~mm}$. The (low friction) polymer guide tube for the projectile was stabilised by a rigid steel support structure, consisting of three stays attached to a collar. The composite plate sample was clamped by two $(170 \times 170 \times 3 \mathrm{~mm})$ steel plates, each with a circular aperture of $120 \mathrm{~mm}$ diameter, bolted to the steel supporting scaffold.

The velocity of the projectile was measured by a light-emitting diode (LED) - light dependent resistor (LDR) system. The projectile, following its release, would block the light emitted from the LED within an LED-LDR pair. This caused a sudden increase in LDR resistance from the reduction in incident light intensity, followed by a rapid decrease when the projectile subsequently unblocked the LED beam. A Labjack U6 data acquisition device was used for monitoring the voltage change of the LDRs during the impact process; the scan rate was set at 25000 scans per second. Knowing the vertical distance between two LED/LDR pairs $(30 \mathrm{~mm})$, the average velocity between them could be calculated from the time interval provided by the two LDR voltage curves. Since the projectile rebounded during all tests in this study, both impact and rebound velocities were measured by the two LED/LDR pairs immediately above the composite sample. Therefore, the energy absorbed by the composite could be defined as the difference between the impact and rebound kinetic energies of the projectile, determined from the velocities and projectile mass. It should be noted that the projectile was not prevented from making 
multiple rebounds on the sample. Consequently, the projectile would finally come to rest on the composite plate after all impact energy had been absorbed by the sample (ignoring any minor contribution from friction effects between projectile and guide tube).

\subsection{Drop weight impact tests and damage measurements}

For the CCPs, impact tests were investigated at three impact velocities: 1.9, 3.0 and $5.8 \mathrm{~m} / \mathrm{s}$. Thus corresponding impact energies were $0.96,2.40$ and $8.96 \mathrm{~J}$ respectively. For the RCPs, just one velocity was selected, i.e. $3.0 \mathrm{~m} / \mathrm{s}$. Six batches of samples were tested at each velocity for both CCPs and RCPs. Immediately following the test, the damage depth was measured at the centre of the plate sample, i.e. at the point with the greatest damage depth. Measurements were made using the depth gauge blade from digital calipers, with steel blocks positioned over the sample for a datum point. Each sample was measured three times to provide a mean value for the damage depth. Damage, such as matrix cracking and fibre-matrix debonding generated during the impact process, was studied through visual observation with image processing software, ImageJ.

\section{Results and discussion}

\subsection{Fibre distribution investigation for RCPs}

It was found that the fibre mat for production of the $2 \% V_{\mathrm{f}} \mathrm{RCP}$ samples was too thick to show any contrast between the fibres and black background. Thus, to study the density and orientation distributions, the entire fibre mat was divided into four thinner mats with equal amounts of fibre. A representative thinner fibre mat is shown in Fig. 2(a). Each thinner mat (which would correspond to $0.5 \% V_{\mathrm{f}}$ ) was then investigated and adjusted separately.

After several adjustments, the final FOD result from the fibre mat in Fig. 2(a) is shown in Fig. 2(b); a circular shape polar plot would indicate a total random fibre distribution [33]. Although there appears to be some directionality around $0^{\circ}, 90^{\circ}, 180^{\circ}$ and $270^{\circ}$, the plot still shows a circular tendency, indicating an approximately random FOD. Fig. 2(c) shows a histogram of the FDD from the 9 grids. The relatively even total pixel brightness values suggest similar quantities of fibre within each grid. Therefore in summary, the findings indicate that these fibre mats could provide approximately isotropic mechanical properties for the RCP samples.

\subsection{Damage mechanisms and energy absorption assessment}

Typical composite plate images taken from the non-impact side after testing are shown in Fig. 3. These images clearly show complex damage mechanisms including matrix cracking and debonding (the lighter region in the vicinity of the sample centres). The composite plates tested at 3.0 and $5.8 \mathrm{~m} / \mathrm{s}$ show a spider's web pattern of cracks, which can be divided into two forms of cracking; i.e. radial and circular cracks. As a consequence of shear stress effects from the plate clamps, some circular cracks can also be observed adjacent to the sample edges; these cracks were not included within the damage analysis below.

Table 1 shows the results of permanent damage depth (i.e. from plastic deformation) with impact velocity and it is clear that the damage depth for both test and control CCPs increases with this velocity. Most importantly, Fig. 4 shows that the test CCPs give a decreased damage depth at all three impact velocities, by up to $29 \%$, compared with control samples. An inverse relationship between decreased damage depth and impact velocity is also observed. By assuming a linear regression, it is indicated that there would be no difference in damage depth between test and control CCPs when the impact velocity reaches $7.7 \mathrm{~m} / \mathrm{s}$. For the RCPs (tested at $3.0 \mathrm{~m} / \mathrm{s}$ ), the damage depth is shallower than the corresponding CCPs in Table 1. Moreover, a greater decrease (29\%) between the test and control RCPs is observed in Fig. 4, compared with the CCPs tested at this velocity. This may be due to the random fibre orientation, 
which could be expected to react more uniformly in all directions to resist external impact forces. We suggest that the decreased damage depth for all VPPMC test samples emanates from fibre residual tension (a result of the prestress). As a result of the downward deflection during impact, residual tension in the fibres produces a force component normal to the fibre direction. This force component will counteract the impact force, thereby reducing damage depth [35].

Table 1

Damage depth results for both test and control CCPs/RCPs at different impact velocities; SE represents the standard error of the mean.

\begin{tabular}{ccccc}
\hline Sample & $\begin{array}{c}\text { Impact Velocity } \\
(\mathrm{m} / \mathrm{s})\end{array}$ & \multicolumn{2}{c}{ Damage Depth $(\mathrm{mm})$} & $\begin{array}{c}\text { Mean Decrease in Damage } \\
\text { Depth }(\% \pm \mathrm{SE})\end{array}$ \\
\hline \multirow{2}{*}{$\mathrm{CCP}$} & 1.9 & $0.73 \pm 0.09$ & $1.02 \pm 0.09$ & $28.92 \pm 4.81$ \\
& 3.0 & $2.96 \pm 0.18$ & $3.70 \pm 0.08$ & $20.21 \pm 3.85$ \\
& 5.8 & $11.01 \pm 0.32$ & $12.21 \pm 0.43$ & $9.58 \pm 2.36$ \\
$\mathrm{RCP}$ & 3.0 & $1.96 \pm 0.24$ & $2.74 \pm 0.26$ & $28.65 \pm 5.01$ \\
\hline
\end{tabular}

Table 2 shows the quantitative results of debonded area against impact velocity. As observed with results from Charpy impact tests with unidirectional beam-shaped samples [23, 30, 32, 36], shear stresses at the fibre-matrix interfaces in VPPMCs result in a triggering effect, which promotes debonding; therefore larger debonded areas are observed on test CCPs, compared with their control counterparts. As discussed with damage depth above, Fig. 5 shows that the increase in debonded area between test and control CCPs also decreases with increasing impact velocity, from $27 \%$ at $1.9 \mathrm{~m} / \mathrm{s}$ to $12.5 \%$ at $5.8 \mathrm{~m} / \mathrm{s}$. Also, linear regression predicts that there will be no difference in debonded area between test and control CCPs when the impact velocity reaches $9.2 \mathrm{~m} / \mathrm{s}$. Table 2 shows a smaller debonded area for RCPs compared with CCPs, in both test and control samples. Moreover, in Table 2 and Fig. 5, there appears to be no difference in debonded areas between test and control RCPs. We suggest that these observations may result from the randomly orientated fibres following curved paths within the RCPs, so they would respond less collectively, compared with the layers of parallel fibres in the CCPs. The less collective response could impede crack propagation (debonding) at the fibre-matrix interfaces and, in particular, weaken the triggering effect in test RCPs.

Table 2

Debonded area results for both test and control CCPs/RCPs at different impact velocities; SE represents the standard error of the mean.

\begin{tabular}{|c|c|c|c|c|}
\hline \multirow{2}{*}{ Sample } & \multirow{2}{*}{$\begin{array}{l}\text { Impact Velocity } \\
(\mathrm{m} / \mathrm{s})\end{array}$} & \multicolumn{2}{|c|}{ Debonded Area $\left(\mathrm{cm}^{2}\right)$} & \multirow{2}{*}{$\begin{array}{c}\text { Mean Increase in Debonded } \\
\text { Area }(\% \pm \mathrm{SE})\end{array}$} \\
\hline & & Test \pm SE & Control $\pm \mathrm{SE}$ & \\
\hline \multirow[t]{3}{*}{$\mathrm{CCP}$} & 1.9 & $8.22 \pm 0.57$ & $6.47 \pm 0.39$ & $26.99 \pm 0.46$ \\
\hline & 3.0 & $16.66 \pm 0.54$ & $13.78 \pm 0.36$ & $20.99 \pm 3.43$ \\
\hline & 5.8 & $40.63 \pm 0.76$ & $36.22 \pm 0.84$ & $12.49 \pm 3.42$ \\
\hline $\mathrm{RCP}$ & 3.0 & $12.06 \pm 0.53$ & $12.17 \pm 0.62$ & $-0.53 \pm 2.64$ \\
\hline
\end{tabular}


Jevons [15] utilised instrumented falling weight impact testing to study the characteristics of elastically prestressed E-glass/epoxy laminates, by comparing their impact behaviour at different prestress levels and impact velocities. For the optimum $60 \mathrm{MPa}$ prestress level, the EPPMCs showed decreases of $25 \%, 12 \%$ and $\sim 0 \%$ in delamination area compared with unstressed laminates at impact velocities of 1.9, 3.5 and $6.4 \mathrm{~m} / \mathrm{s}$ respectively. Clearly, this decrease with increasing impact velocity is similar to the trends found in Figs. 4 and 5. We speculate here, that the effect of prestress, whether it is elastically or viscoelastically generated, requires a "reaction time" to be effective for influencing the damage mechanisms. Therefore, as impact velocity is increased, there may be insufficient time for the effect of prestress to respond to external forces, leading to similar damage results between test and control samples. The proposed reaction time may be explained as follows. A fibre-reinforced PMC will possess viscoelastic characteristics; thus under impact, even if the fibres could react with almost perfect elasticity (e.g. glass fibres in an EPPMC), the polymeric matrix and fibre-matrix interfaces will not respond instantaneously. There will be some delay due to non-elastic contributions, particularly at the fibrematrix interface/interphase regions. Thus when a PMC is prestressed by its fibres, transfer of the prestress through fibre-matrix interfaces to the matrix itself may require a very short time to create a new "prestress equilibrium" state as the material deforms under impact; i.e. the reaction time. It is therefore possible that the duration of this reaction time may be within a similar timescale to the impact events, leading to the decreasing differences between test and control samples as impact velocity is increased.

Table 3 shows quantitative results of circular crack area and decrease in area between test and control samples. The circular matrix crack area here is defined as the area of the largest circular crack on the composite plate. For CCPs at $1.9 \mathrm{~m} / \mathrm{s}$, no circular crack is seen (see Fig. 3), but as the impact velocity increases, a circular area is observed, this being greater at $5.8 \mathrm{~m} / \mathrm{s}$ compared with $3.0 \mathrm{~m} / \mathrm{s}$. Comparing test CCPs with control counterparts, the circular crack area shows a $\sim 35 \%$ decrease at $3.0 \mathrm{~m} / \mathrm{s}$; however, the decrease is insignificant at $5.8 \mathrm{~m} / \mathrm{s}$. This finding appears to concur with the damage depth and debonded area data, in that less difference is observed between test and control samples at higher impact velocities. Similarly (at $3.0 \mathrm{~m} / \mathrm{s}$ ), the test RCPs also show a smaller circular area than their control counterparts by $\sim 48 \%$. Moreover, a smaller circular area is obtained from the RCPs compared with corresponding CCPs at $3.0 \mathrm{~m} / \mathrm{s}$.

Table 3

Circular crack area results (measured from the largest circular crack) for both test and control CCPs/RCPs at different impact velocities; SE represents the standard error of the mean.

\begin{tabular}{ccccc}
\hline Sample & $\begin{array}{c}\text { Impact Velocity } \\
(\mathrm{m} / \mathrm{s})\end{array}$ & \multicolumn{2}{c}{ Circular Crack Area $\left(\mathrm{cm}^{2}\right)$} & Mean Decrease in Crack \\
Test \pm SE & Control \pm SE & Area \pm SE) \\
\hline \multirow{2}{*}{ CCP } & 1.9 & - & - & - \\
& 3.0 & $23.71 \pm 4.64$ & $37.26 \pm 1.71$ & $34.67 \pm 14.93$ \\
& 5.8 & $53.37 \pm 4.25$ & $58.90 \pm 5.96$ & $4.93 \pm 11.34$ \\
$\mathrm{RCP}$ & 3.0 & $7.16 \pm 2.77$ & $15.11 \pm 3.11$ & $48.29 \pm 19.24$ \\
\hline
\end{tabular}

For the radial matrix cracks in our work, the longest crack (almost to the full width of the plate) lies along the fibre layer direction in proximity to the non-impact side and multiple shorter cracks in other directions can be seen on CCP samples (see Fig. 3). In contrast, the length of radial cracks within the RCPs appear to show little or no difference in direction and this can be attributed to the approximately isotropic distribution of the nonwoven fibre mat. The total radial crack length data for all composite plates are summarised in Table 4. For both test and control CCPs, it is clear that the total radial crack 
length increases with impact velocity. In addition, a longer total radial crack length can be seen on RCPs $(\sim 60 \mathrm{~cm})$ compared with the CCPs tested at $3.0 \mathrm{~m} / \mathrm{s}(\sim 45 \mathrm{~cm})$. We suggest that this longer radial crack length in the RCPs arises from two mechanisms, i.e. (i) numerous fibre ends acting as intrinsic initial flaws within the RCPs and (ii) a less collective response from the curved discontinuous fibres to impede crack propagation. For both CCP and RCP samples, Table 4 shows that there is no apparent difference in the total radial crack length between test and control.

\section{Table 4}

Total radial crack length results for both test and control CCPs/RCPs at different impact velocities; SE represents the standard error of the mean.

\begin{tabular}{|c|c|c|c|c|}
\hline \multirow{2}{*}{ Sample } & \multirow{2}{*}{$\begin{array}{l}\text { Impact Velocity } \\
\qquad(\mathrm{m} / \mathrm{s})\end{array}$} & \multicolumn{2}{|c|}{ Total Radial Crack Length (cm) } & \multirow{2}{*}{$\begin{array}{l}\text { Mean Decrease in Crack } \\
\text { Length }(\% \pm \text { SE) }\end{array}$} \\
\hline & & Test $\pm \mathrm{SE}$ & Control $\pm \mathrm{SE}$ & \\
\hline \multirow[t]{3}{*}{$\mathrm{CCP}$} & 1.9 & $33.79 \pm 2.00$ & $32.82 \pm 0.83$ & $-2.60 \pm 3.60$ \\
\hline & 3.0 & $44.82 \pm 1.48$ & $48.51 \pm 1.73$ & $6.96 \pm 4.56$ \\
\hline & 5.8 & $71.36 \pm 2.62$ & $77.15 \pm 1.34$ & $7.47 \pm 3.15$ \\
\hline RCP & 3.0 & $60.69 \pm 5.53$ & $60.07 \pm 3.63$ & $-1.89 \pm 8.43$ \\
\hline
\end{tabular}

Observations demonstrate that all circular cracks are initiated at the impact surface of the composite plates, propagating downwards through the depth of the composite plate, as illustrated in Fig. 6. This phenomenon was also observed in a nano-indentation experiment of a brittle thin film on a ductile substrate [37]. Stress analysis based on finite element methods indicated a peak principal stress (mainly radial tensile stress) at the film impact surface, which was believed to induce circular crack formation [37, 38]. It was also reported that low velocity impact and indentation experiments could both be treated as quasi-static [2, 39-42]; the film in Ref. [37] and composite plates in this study also both show brittle damage characteristics. Therefore, we may infer that the initiation of circular cracks at the composite plate impact surface also results from radial tensile stresses concentrated at the impact surface. In contrast to the circular cracks, the radial cracks are observed to initiate from the non-impacted side of the composite plate (see Fig. 6). This phenomenon could explain the radial crack patterns from the CCPs. After formation of the radial cracks on the non-impacted side of the CCP, those cracks, which run in the fibre direction, propagate almost over the full width of the plate. In other directions however, the fibre layer would be effective in impeding crack propagation, leading to the observed shorter radial cracks.

Studies at Tsinghua University into the characteristics of windshield cracking under low velocity impact conditions are of interest here. They found that the hoop stress field (leading to radial cracking) was more prominent than the radial stress field (leading to circular cracking). Since radial crack growth was more efficient in releasing energy, the crack was prone to propagate radially rather than circularly. A high-speed camera revealed that the formation of all radial cracks preceded circular crack formation [43$45]$ and this concurs with our findings. For CCPs tested at $1.9 \mathrm{~m} / \mathrm{s}$, only radial matrix cracks were observed (Fig. 3), but with increasing impact velocity, circular matrix cracks were also generated in response to impact energy in excess of that absorbed by radial crack generation. Since longer total radial crack lengths were found from RCPs (compared with the corresponding CCPs) tested at $3.0 \mathrm{~m} / \mathrm{s}$, these would have absorbed more energy; thus fewer circular cracks would be required to absorb energy in excess of this, in accordance with the observed smaller circular crack areas. Our previous investigations have suggested that the matrix compression induced by prestressing fibres can impede crack propagation and formation [36]. The effect only seems to influence the circular cracks and not the radial cracks in this study, however. This may be due to the relatively low $V_{\mathrm{f}}(2 \%)$, resulting in insufficient compressive 
stresses being generated to impede radial crack propagation in the test samples. Nevertheless, compressive stress magnitude within the test samples may be effective in impeding the formation of circular cracks some distance from the impact point, due to the relatively minor radial stress field. This would lead to the observed decrease in circular damage area.

Impact energy absorption results are shown in Table 5 and it should be noted that the values are only for the first impact. Given the high energy absorption values in Table 5, it can be assumed that the majority of the damage is generated through the first impact; therefore, the damage mechanisms discussed above caused by multiple impacts, may still be applicable in discussing the energy absorption here. For CCPs, the energy absorption rises from $\sim 65 \%$ to $\sim 90 \%$ of the impact energy as impact velocity increases from $1.9 \mathrm{~m} / \mathrm{s}$ to $5.8 \mathrm{~m} / \mathrm{s}$. The energy absorption value is a comprehensive expression of the total amount of energy dissipated by the composite sample through damage formation during the impact process [46]. Shallower damage depth (from plastic deformation) and smaller circular crack area suggest less energy absorbed by the test samples. Nevertheless, the larger debonded area observed in test CCPs indicates more energy absorption. Although for both CCPs and RCPs, only a few percent decrease in energy absorption between test and control samples is observed, the relatively consistent decreases may still imply a slightly higher impact resistance for both types of VPPMC plates, which could be increased with a higher $V_{\mathrm{f}}$.

\section{Table 5}

Impact energy absorption (percent numbers of the initial impact energy) results from the first impact for both test and control CCPs/RCPs at different impact velocities; SE represents the standard error of the mean.

\begin{tabular}{ccccc}
\hline Sample & $\begin{array}{c}\text { Impact Velocity } \\
(\mathrm{m} / \mathrm{s})\end{array}$ & \multicolumn{2}{c}{ Impact energy absorption $(\%)$} \\
Test $\pm \mathrm{SE}$ & Control \pm SE & $\begin{array}{c}\text { Mean Decrease in Energy } \\
(\% \pm \text { SE) }\end{array}$ \\
\hline \multirow{2}{*}{$\mathrm{CCP}$} & 1.9 & $66.77 \pm 0.82$ & $68.76 \pm 1.26$ & $2.78 \pm 1.57$ \\
& 3.0 & $76.70 \pm 1.19$ & $79.53 \pm 0.65$ & $3.55 \pm 1.49$ \\
& 5.8 & $89.36 \pm 0.56$ & $90.70 \pm 0.70$ & $1.45 \pm 1.16$ \\
$\mathrm{RCP}$ & 3.0 & $73.85 \pm 1.99$ & $77.12 \pm 1.92$ & $4.23 \pm 0.99$ \\
\hline
\end{tabular}

Some consideration should be given to the final damage patterns shown in Fig. 3, as they result from multiple impacts discussed above. The projectile does not penetrate through the CCPs or RCPs, thus all test and control samples would eventually absorb the same amount of the total impact energy (assuming negligible effects from friction). Therefore, since total energy absorbed remains constant, the shallower damage depth from VPPMCs may also support the application of two-dimensional VPPMCs for low velocity impact protection in practical applications [36].

\subsection{Fibre prestress and volume fraction}

The purpose of this paper was to report the first findings of impact properties from flat plate VPPMCs. To ascertain the influence of impact velocity has been of primary importance; however, key parameters such as fibre prestress level and $V_{\mathrm{f}}$ were not optimised to determine maximum improvement. For EPPMC plate samples, Jevons [15] found an optimum prestress level ( $60 \mathrm{MPa})$ to improve drop-weight impact properties, similar to an earlier result with EPPMC samples using Charpy impact tests [47]. The creep treatment for prestress generation in the current study ( $330 \mathrm{MPa}$ for $24 \mathrm{~h}$ ) was the standard condition used in previous work on VPPMCs [17, 21-26, 28-30,36]. Nevertheless, a recent study with Charpy impact 
tested VPPMCs has suggested an optimum $24 \mathrm{~h}$ creep stress, with $460 \mathrm{MPa}$ providing greater improvements in impact toughness than $330 \mathrm{MPa}$ or $590 \mathrm{MPa}$ [48].

As reported in Section 2.1, the yarn stretching capacity in this work limited $V_{\mathrm{f}}$ for all samples to $2 \%$. Therefore, it is encouraging to note that despite the low $V_{\mathrm{f}}$, measurable improvements in impact resistance could be obtained. In previous work, when compared with control counterparts, VPPMCs under Charpy impact conditions showed a slight improvement in energy absorption with increasing Vf over the range studied (3.3-16.6\% $V_{\mathrm{f}}$ ) [30] and, under tensile testing conditions, an optimum $V_{\mathrm{f}}$ of $35-40 \%$ was reported for maximising strength, modulus and toughness [24]. Thus it may be inferred that greater improvements to drop-weight impact resistance would be expected at higher $V_{\mathrm{f}}$ values.

\section{Conclusions}

The impact behaviour of thin flat-plate VPPMCs has been investigated by using drop weight impact testing. In addition to the production and evaluation of cross-composite plates with continuous fibre layers at $0^{\circ}$ and $90^{\circ}$ directions (CCPs), we have reported on the first VPPMC plates produced with randomly distributed discontinuous fibres (RCPs). The differences in damage patterns and energy absorption have been compared between VPPMCs and their unstressed control counterparts. The main findings are:

i. $\quad$ For CCPs, a decreased damage depth and increased debonded area were observed for VPPMC samples compared with control counterparts; while for RCPs, the changes were restricted to a reduction in damage depth. The decrease in damage depth from VPPMC samples was $20 \%$ for CCPs and $\sim 30 \%$ for RCPs at $3.0 \mathrm{~m} / \mathrm{s}$ impact velocity. For CCPs, as impact velocity was increased from 1.9 to $5.8 \mathrm{~m} / \mathrm{s}$, the differences in damage patterns showed a decreasing trend towards zero at 7.7 and $9.2 \mathrm{~m} / \mathrm{s}$ in damage depth and debonded area respectively. This indicated that any influence from viscoelastically prestressed fibres would only be effective for impact velocities lower than $\sim 10 \mathrm{~m} / \mathrm{s}$.

ii. For both CCPs and RCPs, VPPMC samples showed smaller circular damage areas than corresponding control samples. Nevertheless, no significant differences were observed in the total radial crack lengths between test and control samples. The latter is believed to result from a more prominent hoop stress during the impact process. Thus the magnitude of compressive stresses within test samples may not be sufficient to impede radial crack propagation; this may be attributed to the low $V_{\mathrm{f}}$ used in this work.

iii. In comparison with control CCPs and RCPs, a slight decrease in energy absorption (from the first impact) was observed for corresponding VPPMC samples. This suggests that the VPPMCs provide higher impact resistance which concurs with the reduced damage depth in (i).

Our work has demonstrated that viscoelastically generated fibre prestress could alter the damage mechanisms of flat-plate composites subjected to low velocity impact. The modest increase in impact resistance (observed as reduced damage depth) from VPPMCs supports the possibility of using flat plate VPPMCs for impact protection. To achieve more notable improvements, future work would require an evaluation of samples with a range of $V_{\mathrm{f}}$ and prestress values.

\section{Acknowledgements}

Support from the Hull-China Scholarship Council scheme, for one of the authors (YQ), is gratefully acknowledged. We also wish to thank the mechanical workshop staff in the Department of Engineering, particularly Russ Kenyon, for their technical support. 


\section{References}

[1] Cantwell WJ, Morton J. The impact resistance of composite materials - a review. Compos. 1991;22(5):347-62.

[2] Richardson M, Wisheart M. Review of low-velocity impact properties of composite materials. Compos Part A. 1996;27(12):1123-31.

[3] Sutherland L, Soares CG. Impact characterisation of low fibre-volume glass reinforced polyester circular laminated plates. Int J Impact Eng. 2005;31(1):1-23.

[4] Bensadoun F, Depuydt D, Baets J, Verpoest I, Van Vuure A. Low velocity impact properties of flax composites. Compos Struct. 2017;176:933-44.

[5] Walker L, Sohn M-S, Hu X-Z. Improving impact resistance of carbon-fibre composites through interlaminar reinforcement. Compos Part A. 2002;33(6):893-902.

[6] Sebaey T, Mahdi E. Using thin-plies to improve the damage resistance and tolerance of aeronautical CFRP composites. Compos Part A. 2016;86:31-8.

[7] Kim J-K, Sham M-L. Impact and delamination failure of woven-fabric composites. Compos Sci Technol. 2000;60(5):745-61.

[8] Naik NK, Sekher YC, Meduri S. Damage in woven-fabric composites subjected to low-velocity impact. Compos Sci Technol. 2000;60(5):731-44.

[9] Baucom J, Zikry M. Low-velocity impact damage progression in woven E-glass composite systems. Compos Part A. 2005;36(5):658-64.

[10] Atas C, Sayman O. An overall view on impact response of woven fabric composite plates. Compos Struct. 2008;82(3):336-45

[11] Hart KR, Chia PX, Sheridan LE, Wetzel ED, Sottos NR, White SR. Mechanisms and characterization of impact damage in 2D and 3D woven fiber-reinforced composites. Compos Part A. 2017;101:432-43.

[12] Bull D, Scott A, Spearing S, Sinclair I. The influence of toughening-particles in CFRPs on low velocity impact damage resistance performance. Compos Part A. 2014;58:47-55.

[13] Thanomsilp C, Hogg P. Penetration impact resistance of hybrid composites based on commingled yarn fabrics. Compos Sci Technol. 2003;63(3-4):467-82.

[14] Hogg PJ. Toughening of thermosetting composites with thermoplastic fibres. Mater Sci Eng A. 2005;412(1-2):97-103.

[15] Jevons MP. The effects of fibre pre-stressing on the impact performance of composite laminates [PhD thesis]: Cranfield University; 2004.

[16] Mostafa NH, Ismarrubie Z, Sapuan S, Sultan M. Fibre prestressed polymer-matrix composites: a review. J Compos Mater. 2017;51(1):39-66.

[17] Fancey KS. Fiber-reinforced polymeric composites with viscoelastically induced prestress. J Adv Mater. 2005;37(2):21-9.

[18] Krishnamurthy S. Pre-stressed advanced fibre reinforced composites fabrication and mechanical performance [PhD thesis]: Cranfield University; 2006.

[19] Daynes S, Diaconu C, Potter K, Weaver P. Bistable prestressed symmetric laminates. J Compos Mater. 2010;44(9):1119-37.

[20] Mostafa NH. Stress relaxation effect on fatigue life of biaxial prestressed woven E-glass/polyester composites. Mech Time-Depend Mat. 2019:1-11.

[21] Fancey KS. Investigation into the feasibility of viscoelastically generated pre-stress in polymeric matrix composites. Mater Sci Eng A. 2000;279(1):36-41. 
[22] Fancey KS. Viscoelastically prestressed polymeric matrix composites: An overview. J Reinf Plast Compos. 2016;35(17):1290-301.

[23] Fancey KS, Fazal A. Prestressed polymeric matrix composites: Longevity aspects. Polym Compos. 2016;37(7):2092-7.

[24] Pang JW, Fancey KS. Analysis of the tensile behaviour of viscoelastically prestressed polymeric matrix composites. Compos Sci Technol. 2008;68(7):1903-10.

[25] Pang JW, Fancey KS. The flexural stiffness characteristics of viscoelastically prestressed polymeric matrix composites. Compos Part A. 2009;40(6):784-90.

[26] Fazal A, Fancey KS. Viscoelastically generated prestress from ultra-high molecular weight polyethylene fibres. J Mater Sci. 2013;48(16):5559-70.

[27] Qin Y, Fancey KS. Towards “green” viscoelastically prestressed composites: Cellulose fibre reinforcement. Compos Part B. 2018;154:439-48.

[28] Wang B, Fancey KS. A bistable morphing composite using viscoelastically generated prestress. Mater Lett. 2015;158:108-10.

[29] Wang B, Ge C, Fancey KS. Snap-through behaviour of a bistable structure based on viscoelastically generated prestress. Compos Part B. 2017;114:23-33.

[30] Fazal A, Fancey KS. Viscoelastically prestressed polymeric matrix composites-effects of test span and fibre volume fraction on Charpy impact characteristics. Compos Part B. 2013;44(1):472-9.

[31] Fazal A, Fancey KS. UHMWPE fibre-based composites: Prestress-induced enhancement of impact properties. Compos Part B. 2014;66:1-6.

[32] Wang B, Fancey KS. Towards optimisation of load-time conditions for producing viscoelastically prestressed polymeric matrix composites. Compos Part B. 2016;87:336-42.

[33] Tunák M, Linka A. Analysis of planar anisotropy of fibre systems by using 2D Fourier transform. Fibres Text East Eur. 2007;15(5-6):64-5.

[34] Chapman LC, Wilson RDG. Development of a moulding and testing facility for research into viscoelastically prestressed polymeric matrix composites [MEng group theses]: University of Hull; 2014.

[35] Motahhari S, Cameron J. Fibre prestressed composites: improvement of flexural properties through fibre prestressing. J Reinf Plast Compos. 1999;18(3):279-88.

[36] Fancey KS. Viscoelastically prestressed polymeric matrix composites-Potential for useful life and impact protection. Compos Part B. 2010;41(6):454-61.

[37] Fu K, Chang L, Ye L, Yin Y. Indentation stress-based models to predict fracture properties of brittle thin film on a ductile substrate. Surf Coat Tech. 2016;296:46-57.

[38] Fu K, Yin Y, Chang L, Shou D, Zheng B, Ye L. Analysis on multiple ring-like cracks in thin amorphous carbon film on soft substrate under nanoindentation. J Phys D. 2013;46(50):505314.

[39] Agrawal S, Singh KK, Sarkar P. Impact damage on fibre-reinforced polymer matrix composite-a review. J Compos Mater. 2014;48(3):317-32.

[40] Ferri R, Sankar BV. Static indentation and low velocity impact tests on sandwich plates. ASME. 1997:485-90.

[41] Pramanik A, Zhang L, Arsecularatne J. Deformation mechanisms of MMCs under indentation. Compos Sci Technol. 2008;68(6):1304-12.

[42] Tan KT, Watanabe N, Iwahori Y. Effect of stitch density and stitch thread thickness on low-velocity impact damage of stitched composites. Compos Part A. 2010;41(12):1857-68.

[43] Chen J, Xu J, Liu B, Yao X, Li Y. Quantity effect of radial cracks on the cracking propagation behavior and the crack morphology. PloS one. 2014;9(7):e98196. 
[44] Chen J, Xu J, Yao X, Liu B, Xu X, Zhang Y, et al. Experimental investigation on the radial and circular crack propagation of PVB laminated glass subject to dynamic out-of-plane loading. Eng Fract Mech. 2013;112:26-40.

[45] Xu J, Li Y, Chen X, Yan Y, Ge D, Zhu M, et al. Characteristics of windshield cracking upon lowspeed impact: numerical simulation based on the extended finite element method. Comp Mater Sci. 2010;48(3):582-8.

[46] Ravandi M, Teo W, Tran L, Yong M, Tay T. Low velocity impact performance of stitched flax/epoxy composite laminates. Compos Part B. 2017;117:89-100.

[47] Motahhari S, Cameron J. Impact strength of fiber pre-stressed composites. J Reinf Plast Compos. 1998;17(2):123-130.

[48] Wang B, Fancey KS. Viscoelastically prestressed polymeric matrix composites: An investigation into fibre deformation and prestress mechanisms. Compos Part A. 2018;111:106-114. 


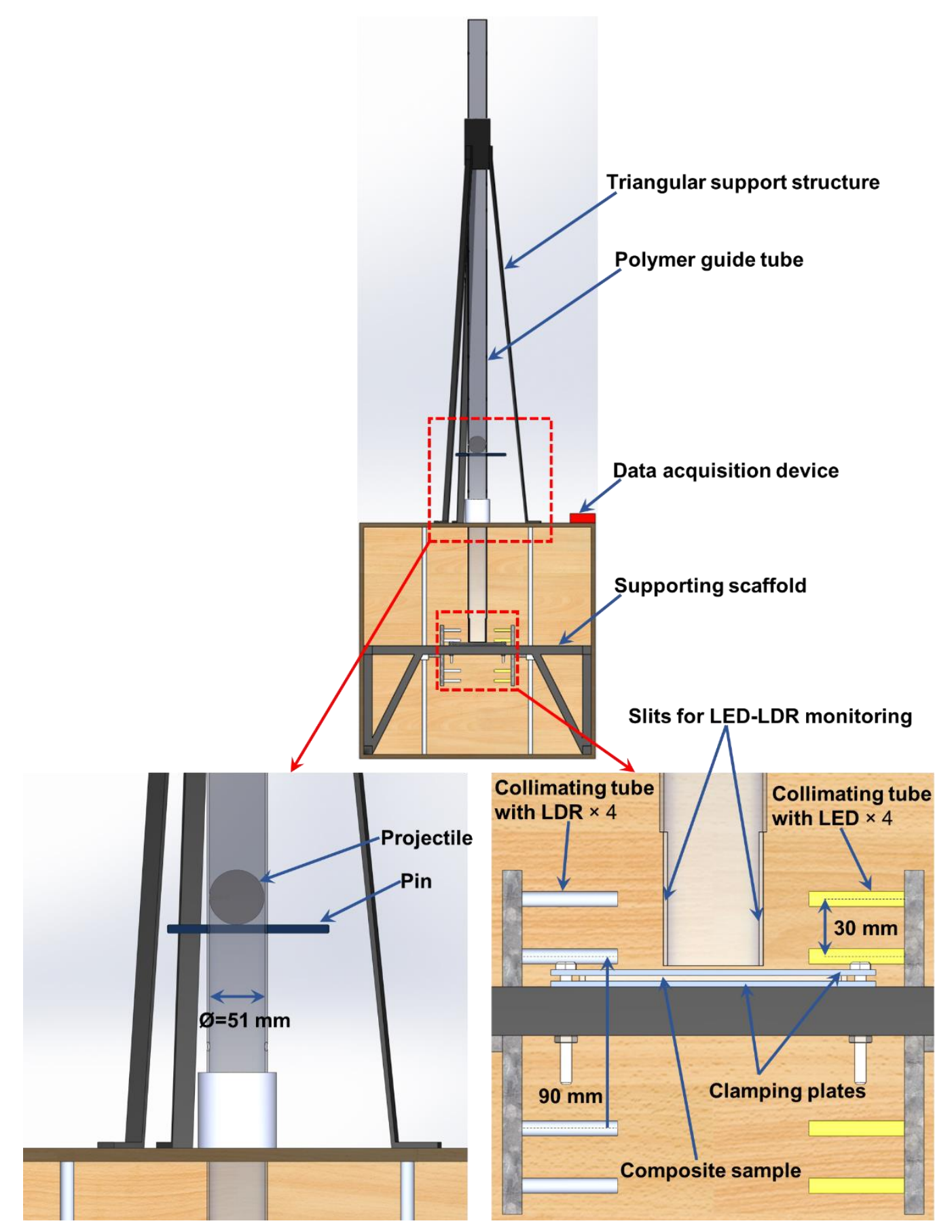

Fig. 1. Schematic diagrams of the drop weight impact test tower, showing the projectile support and monitoring arrangement. 
(a)

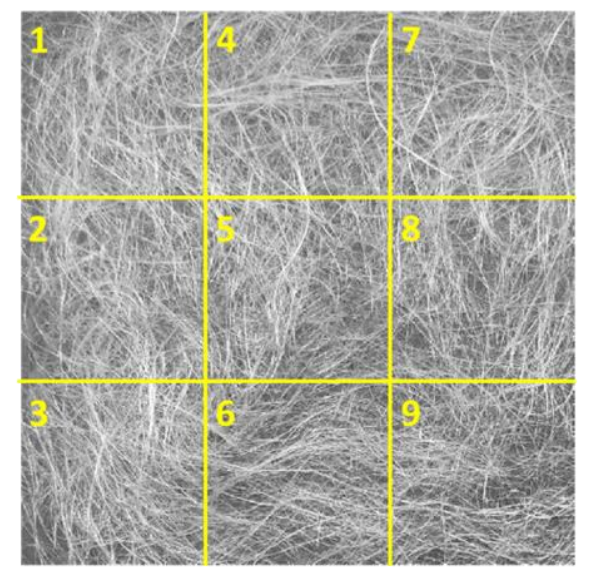

(b)
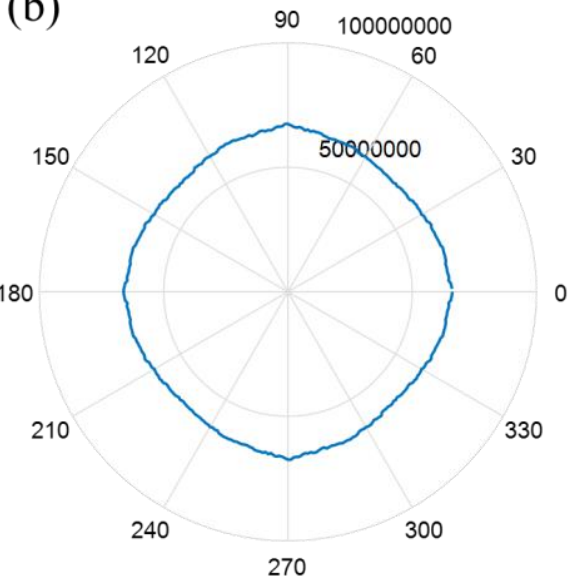

(c)

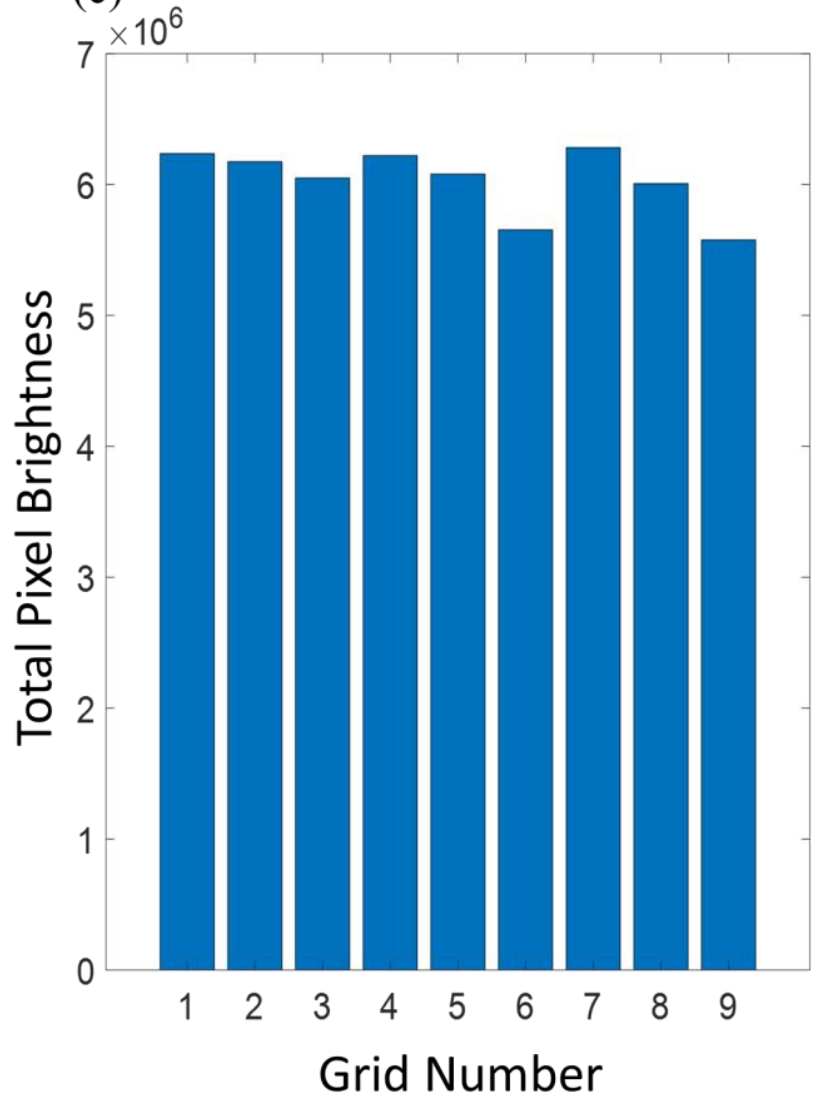

Fig. 2. (a) Optical image of a typical $140 \times 140 \mathrm{~mm}$ nonwoven fibre mat (corresponding to $0.5 \% V_{\mathrm{f}}$ ), divided into nine equal grids; (b) polar plot of the FOD from $0^{\circ}$ to $360^{\circ}$; (c) histogram of the FDD with grid number.

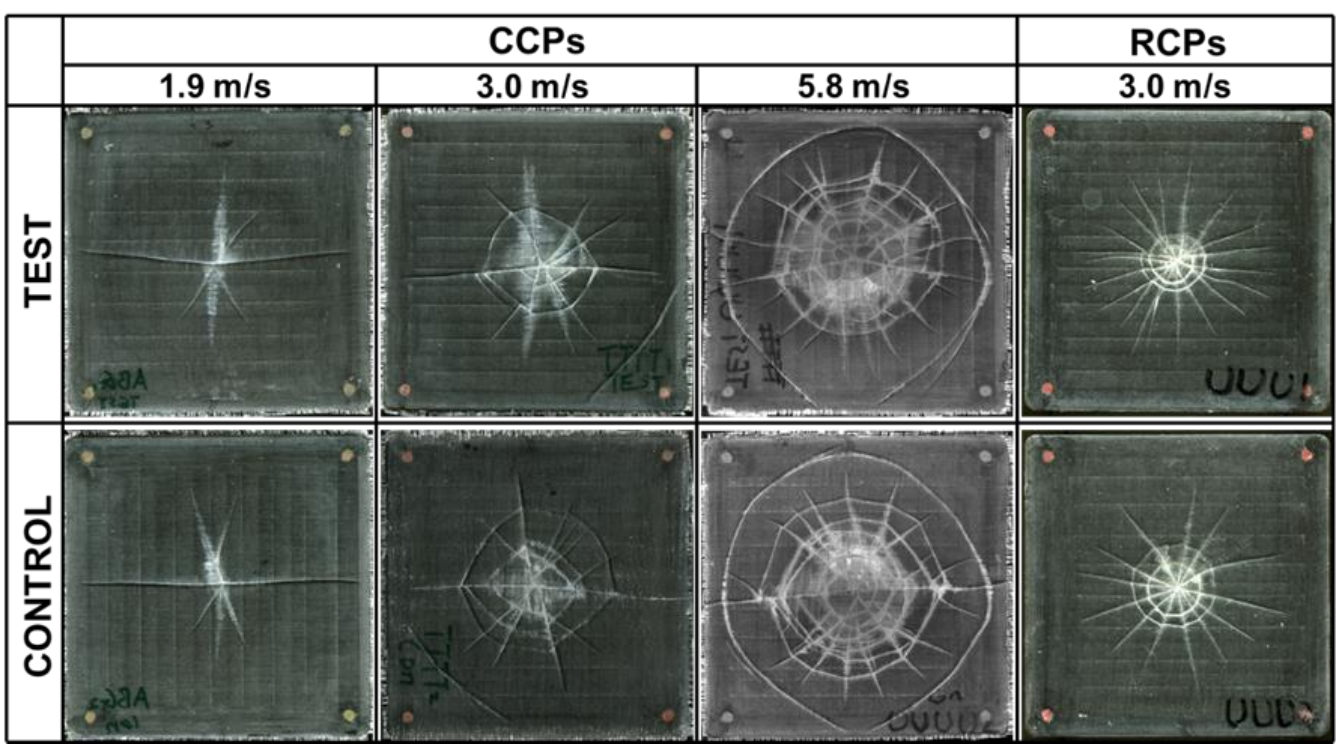

Fig. 3. Typical CCP and RCP damage patterns following drop weight impact tests under projectile rebound conditions at different impact velocities. 


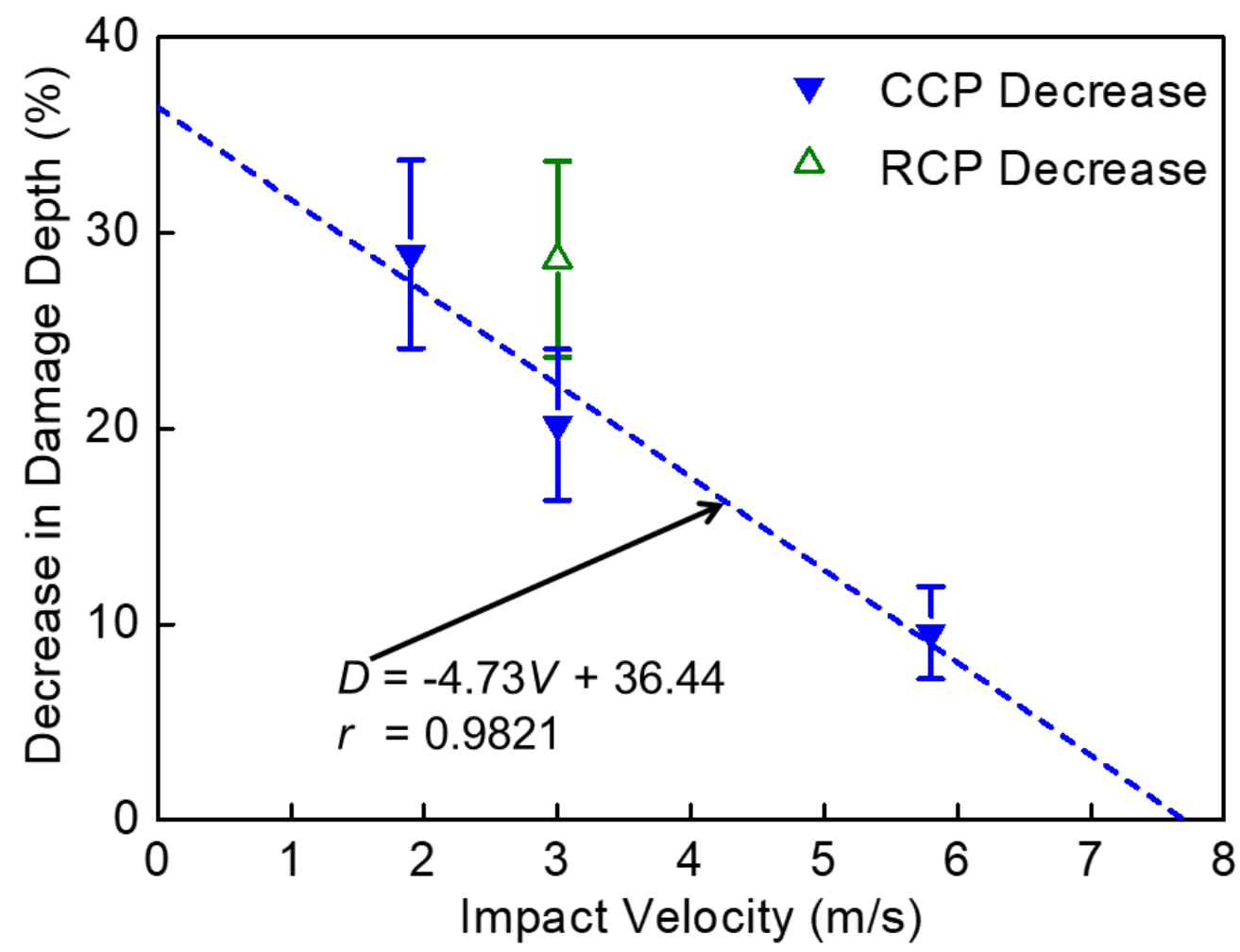

Fig. 4. Decrease in damage depth, with impact velocity, between test and control samples. The dashed line and equation for CCPs are from linear regression; $D$ and $V$ represent the decrease and impact velocity respectively, $r$ is the correlation coefficient.

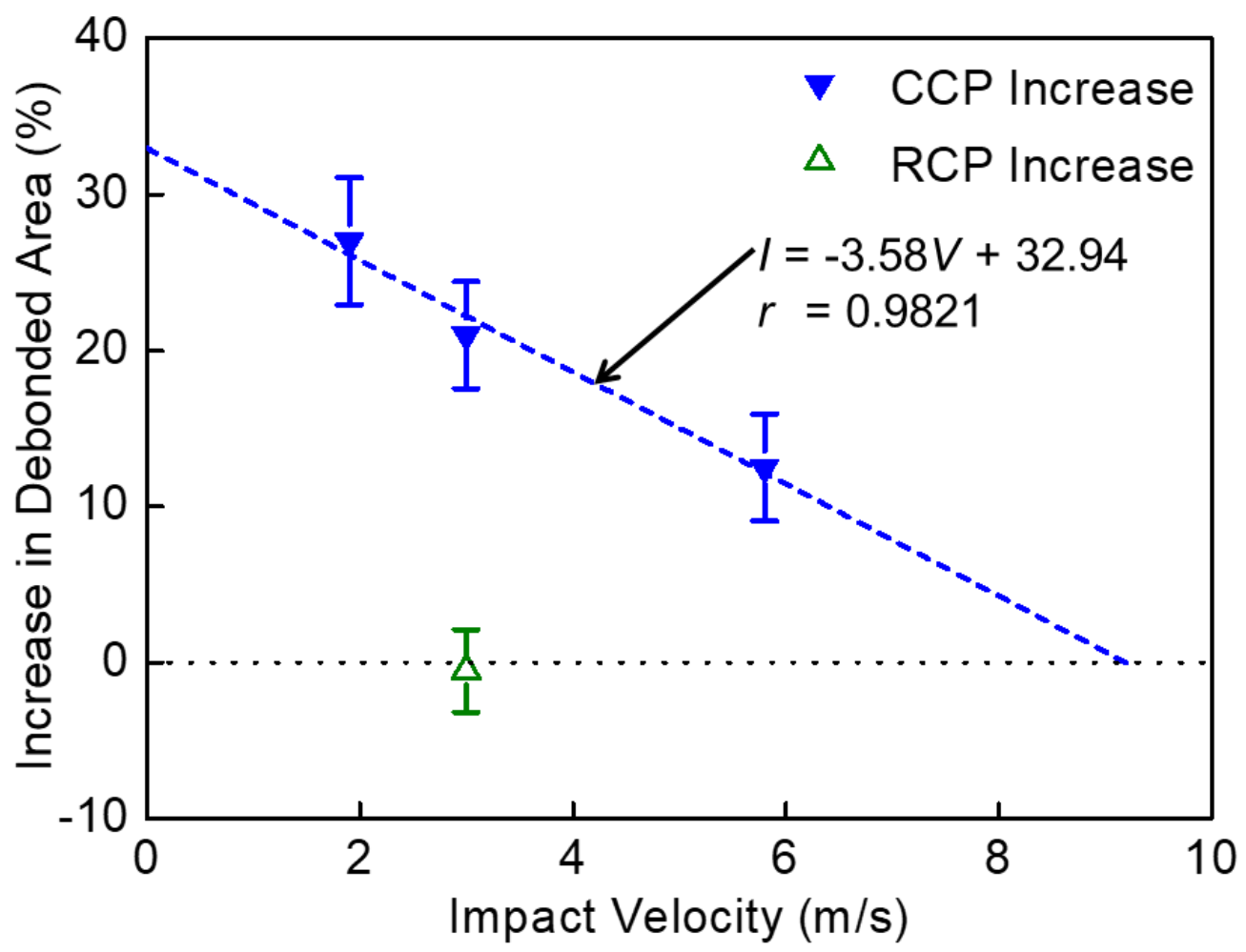

Fig. 5. Increase in debonded area, with impact velocity, between test and control samples. The dashed line and equation for CCPs are from linear regression; $I$ and $V$ represent the increase and impact velocity respectively, $r$ is the correlation coefficient. 


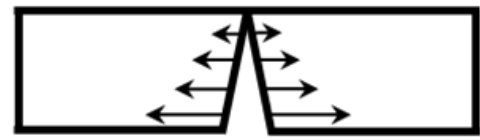

Radial crack
Non-impact side

(Initiates from the non-impact side)

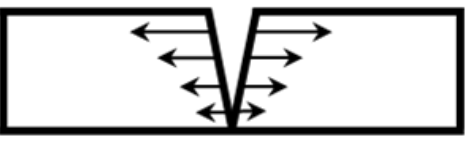

Circular crack

(Initiates from impact side)

Fig. 6. Schematic of the development of radial and circular cracks. 